
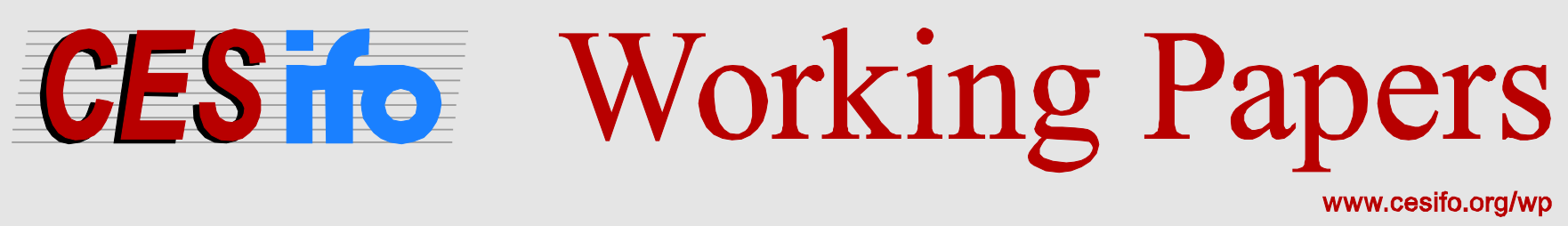

\title{
The Intricacy of Adapting to Climate Change: Flood Protection as a Local Public Goods Game
}

\author{
Anton Bondarev \\ Beat Hintermann \\ Frank C. Krysiak \\ Ralph Winkler
}

\section{CESIFO WORKING PAPER NO. 6382 \\ CATEGORY 10: ENERGY AND CLIMATE ECONOMICS \\ FEBRUARY 2017}

An electronic version of the paper may be downloaded

- from the SSRN website: Www.SSRN.com

- from the RePEc website: Www.RePEc.org

- from the CESifo website: www.CESifo-group.org/wp 


\title{
The Intricacy of Adapting to Climate Change: Flood Protection as a Local Public Goods Game
}

\begin{abstract}
We study adaptation to climate change in a federalist setting. To protect themselves against an increase in flood risk, regional governments choose among adaptation measures that vary with respect to their costs, the level of protection they offer, and the presence and nature of spillovers to neighboring regions. The central government can provide co-funding in response to specific proposals. If it has to deduce the vulnerability of regions by their actions, the resulting adaptation measures are too costly from a social point of view. The results show that adaptation cannot be expected to be efficient without specifically designed incentive schemes.
\end{abstract}

JEL-Codes: C720, C730, H230, H410, H770, Q520, Q540, Q580, R530.

Keywords: climate change, adaptation, federalism, asymmetric information, vertical interaction, spillovers, non-cooperative games, signaling.

\author{
Anton Bondarev \\ Department of Business and Economics \\ University of Basel \\ Basel / Switzerland \\ anton.bondarev@unibas.ch \\ Frank C. Krysiak \\ Department of Business and Economics \\ University of Basel \\ Basel / Switzerland \\ Frank.Krysiak@unibas.ch
}

\author{
Beat Hintermann \\ Department of Business and Economics \\ University of Basel \\ Basel / Switzerland \\ b.hintermann@unibas.ch \\ Ralph Winkler \\ University of Bern \\ Bern / Switzerland \\ rwinkler@vwi.unibe.ch
}

February 17, 2017

This research has been supported by the Swiss National Science Foundation under grant Nr. CRSII1-154404 (Sinergia). 


\section{Introduction}

Climate policy has focused on mitigation of greenhouse gas emissions for more than two decades. But in light of the limited global cooperation, it has become increasingly unlikely that mitigation policies with the necessary scale and scope to prevent serious climate change will be implemented in time. Consequently, increasing attention is paid to adapting to climate change. ${ }^{1}$

Adaptation is commonly seen as being a far simpler problem than mitigation, because it constitutes a local or regional public good rather than a global one, and consequently is less prone to insurmountable free-rider or coordination problems. When adaptation is included in large-scale economic assessments of climate policies, for example in the context of integrated assessment models, it is usually modeled as optimal adaptation (e.g., De Bruin et al., 2009; Agrawala et al., 2011). This implies the view that, in contrast to mitigation, the timely implementation of effective and efficient adaptation measures is not a serious challenge.

In this paper, we contest this notion. While it is true that adaptation poses different problems than mitigation, these are still fairly complex and can easily lead to the implementation of inefficient adaptation measures. Therefore, if adaption is to become a necessary complement (or substitute) to mitigation, more effort needs to be spent on designing policies and institutions that facilitate an efficient choice of adaptation measures.

There are several reasons as to why adaptation to climate change is a complex problem and thus interesting from an economics point of view. First, many adaptation measures have a public good-character and will therefore not be supplied efficiently by private markets. Second, the costs and benefits of adaptation measures can vary across locations, such that adaptation decisions should be (and indeed often are) made by local or regional authorities who know these costs better than the less informed central government. However, adaptation can affect other locations as well. In the context of flood protection,

\footnotetext{
${ }^{1}$ Mitigation refers to the reduction of greenhouse gas emissions, whereas adaptation is defined as "the process of adjustment to actual or expected climate and its effects" (IPCC, 2014, p.5). Adaptation includes a wide range of measures such as constructing protective infrastructure, land use changes, or adjustments of production processes and consumption patterns.
} 
retention areas also protect regions located downriver, whereas flood walls increase expected damages for these regions by increasing the peak runoff volume. Regional governments/voters will generally not include the costs and benefits to other regions when deciding on the optimal level of adaptation. Third, adaptation can be achieved by a variety of means that differ in important aspects, such as the certainty of protection against damages, the delay between the decision to institute a measure and its effect, and the presence and nature of spillovers. Optimal adaptation is therefore not only a question of the level, but also the type of adaptation. Taken together, adaptation is a rather complex decision problem in which actors are likely to behave strategically, and where inefficient outcomes may arise.

We investigate the above problems within a theoretical model, using the example of adaptation to more frequent (or more pronounced) flood events in regions located along the same river. This example is particularly interesting as flood events are expected to contribute substantially to the costs of climate change, and because there is a rich set of strongly differing adaptation options. In our model, two local authorities have to decide among three adaptation measures, one of which is fast and easy to implement (e.g., stapling sand bags at sensitive locations) but offers limited protection, whereas the two other options offer better protection but are more costly and have longer implementation periods. The first of these is associated with positive spillovers to the other region (e.g., a flood retention area or a dam), whereas the second increases damages in the other region (e.g., a flood wall along the river). To implement these two costly adaptation options, local authorities can apply for co-funding to a central government, which uses this instrument to steer and coordinate local decisions. Flood events are uncertain regarding occurrence and magnitude, and the locations can differ regarding their vulnerability to floods.

We show that if regions act without central coordination, adaptation will be generally inefficient, if it takes place at all. Well-designed co-funding by a fully informed central government leads to efficient (albeit delayed) adaptation. However, if the central government has limited information, inefficient adaptation becomes likely again. 
Our analysis shows that even in a relatively simple setting with very limited options for strategic behavior, there is a substantial risk that inefficient adaptation measures will be chosen, and/or that adaptation will be delayed. Adaptation is therefore far from being a "simple" policy problem, especially in the realistic setting of limited information of a central government. There is a risk that local authorities will either engage in an "arms race" in flood protection, where each authority's actions increase flooding risks for the other ones, or use their better information to gain co-funding from the central government for inefficiently large adaptation projects. Although these results are driven by a model focusing on flood protection, similar outcomes are likely to arise in the context of adapting to droughts and adjustments to land use planning, due to the similar pattern of spillovers.

Our model is the first to bring together the three main aspects that characterize adaptation: The problem of choosing between different types of adaptation measures, the necessity of making adaptation decisions at the local level, and the strategic interactions among local players that result from spillovers and asymmetric information. These aspects have been highlighted in numerous case studies (see Section 2), but so far their general implications have not been investigated.

In the next two sections, we provide a brief overview of the related literature and set up our model. In Section 4, we develop a benchmark of fully informed centralized provision of adaptation and compare it to the decentralized equilibria in the full-information and the asymmetric information cases. In Section 5, we analyze the welfare implications, and Section 6 contains robustness checks and proposes some model extensions. Section 7 concludes.

\section{Related Literature}

Although the mitigation of anthropogenic climate change by limiting greenhouse gas emissions has been the dominant goal of climate policy and the focus of academic research, the number of studies about how to adapt to it has increased rapidly in recent years; for a review, see Feenstra et al. (1998) and Leal Filho (2015). However, the vast majority of 
the published work about adaptation to date are case and conceptual studies that do not include a formal model.

Some integrated assessment models explicitly incorporate adaptation (De Bruin et al., 2009; Agrawala et al., 2011), and adaptation has also been specifically considered in the context of international cooperation (Kane and Shogren, 2000; Buob and Stephan, 2011). In these models, adaptation is chosen to minimize social damages from climate change and is thus optimal. However, because adaptation is highly context- and location-specific, and estimates about local climate damages are associated with significant uncertainties (IPCC, 2014) or sometimes are not available at a sufficiently small scale at all (Wilbanks et al., 2007), real adaptation measures are unlikely to be optimally chosen. De Bruin and Dellink (2011) investigate on the importance of various constraints on adaptation, for example due to limited information or inertia in policy-making. They find that limiting the overall quantity and the timing of adaptation lead to potentially high welfare losses.

Placing the decision about adaptation measures with local and regional governments has advantages that have been formalized in Oates' (1972) decentralization theorem, provided that they possess better information about the local costs and benefits of adaptation than the federal government and that there are no spillovers. A number of papers show that the decentralized provision of public goods is efficient if households and/or firms can move freely (Boadway, 1982; Mansoorian and Myers, 1993; Richter and Wellisch, 1996; Bucovetsky, 2011). ${ }^{2}$ This "incentive equivalence" result persists if the public good is associated with spillovers, although coordination may be needed to obtain an efficient outcome if the game between different jurisdictions supports multiple equilibria (Wellisch, 1994; Hoel and Shapiro, 2003). If migration is costly or delayed, however, incentive equivalence breaks down and regions will generally not coordinate their tax and expenditure policies (Hoel, 2004; Hoel and Shapiro, 2004; Myers and Papageorgiou, 1997).

\footnotetext{
${ }^{2}$ The underlying reason is that due to free migration, utility is equalized across regions, such that local governments end up jointly maximizing overall welfare despite focusing on the welfare of their respective constituents.
} 
These studies are based on head taxes that equal the value of public good provision (known as "benefit" taxes), ${ }^{3}$ and they focus on the strategic interaction between governments on the same hierarchical level. In this paper, we abstract from taxation but explicitly allow for the presence of a central government, and thus for vertical interaction between different levels of governments, in addition to the horizontal competition between regional governments. There is a growing consensus that, due to the heterogeneity of adaptation measures with respect to their geographic scale, adaptation policy should be coordinated between different hierarchical levels of government (IPCC, 2014, p. 25). Amundsen et al. (2010) identify information deficits and the lack of coordination between central and local governments in Norway as the major obstacles to efficient adaptation measures, whereas Krysanova et al. (2010) report that the main obstacle to efficient adaptation strategies in six large river basins is a lack of horizontal cooperation. Glicksman (2010) focuses on the division of climate change adaptation policy between the US federal government and state and local governments from a legal perspective and argues that the federal government has an important role, mainly due to spillovers. Cooperation among different levels of government can also be motivated by equity concerns (see, e.g., Aakre and Rübbelke, 2010).

A handful of previous studies do employ a truly federalist structure. Silva and Caplan (1997) consider a pollution externality that is jointly managed by the central and regional governments (but using different policy instruments), and where the central government has the ability to set interregional transfers. The model outcome is efficient, but only if local governments act as policy leaders. Caplan et al. (2000) extend this result to the presence of perfect mobility, and Caplan and Silva (2011) allow for imperfect mobility and impure public goods. ${ }^{4}$

\footnotetext{
${ }^{3}$ In general, the presence of nonbenefit taxation (e.g., taxes on income, capital or property) leads to an inefficient provision of public goods, even if they are strictly local (for reviews, see Boadway and Tremblay, 2012; Bruehlhart et al., 2015), and to an trade-off between equity and inefficiency (Bucovetsky, 2003). Tax competition models that allow for interjurisdictional spillovers of public goods include Bjorvatn and Schjelderup (2002), Eichner and Runkel (2012) and Kuhlmey and Hintermann (2016). In general, incentives to free-ride and to engage in tax competition interact, but with the exception of the special case considered in Ogawa and Wildasin (2009), both types of inefficiencies persist.

${ }^{4}$ Köthenbürger (2004) also allows for a vertical interaction between governments and allows for (capital) tax competition, but he abstracts from spillovers associated with the locally produced public good.
} 
A recent strand of the literature, labeled as "second-generation" models of fiscal federalism by Oates (2005), explicitly models information asymmetries between the central and regional governments, which is an important justification for decentralized action in the first place. Persson and Tabellini (1996) illustrate the trade-off between interregional insurance and moral hazard that arises if redistribution is based on ex-post realizations of shocks, as regions may have an incentive to institute policies that increase the local risk, knowing that they will receive federal assistance. ${ }^{5}$ Motivated by hurricane Katrina, Goodspeed and Haughwout (2012) model regional investment to reduce the risk of future weather or flood damages and show that interregional redistribution, coupled with an inability of the central government to observe regional investment choices, leads to an inefficiently low level of precautionary investment.

A number of studies analyze the effectiveness of intergovernmental grants to support the local provision of strictly local public goods under different informational barriers and show that private information leads to inefficiencies in local public provision and interregional redistribution. For example, Cremer et al. (1996) and Bucovetsky et al. (1998) focus on asymmetric information about local preferences; Raff and Wilson (1997), Cornes and Silva (2003), Huber and Runkel (2006) and Breuillé and Gary-Bobo (2007) model informational barriers with respect to the local technology to produce the public good; and Bordignon et al. (2001) assume that the central government only observes the regional tax rate but not the tax base, and thus not the expenditure on local public goods. In general, the presence of asymmetric information renders the provision of local public goods inefficient, typically measured as a departure from the Samuelson rule. Using a model that shares many similarities with ours, Besfamille (2003) finds that asymmetric information about local preferences leads to overspending on local public projects, as logal governments exploit their informational advantage.

\footnotetext{
${ }^{5} \mathrm{~A}$ qualitatively similar argument is made by Sanguinetti and Tommasi (2004). This literature also includes models focusing on the difficulties of the central government to commit to its policies even after regions make strategic choices (e.g., Akai and Sato, 2008; Besfamille and Lockwood, 2008; Breuillé et al., 2010). Our paper abstracts from these issues and assumes that the central government can fully commit.
} 
Among these second-generation models, only Lockwood (1999) allows for interregional spillovers. ${ }^{6}$ In his setting, regions are identical ex-ante but subject to idiosyncratic shocks, which cannot be observed by the central government (this contrasts with our setup where regions differ in their vulnerability to climate change ex-ante). The presence of spillovers leads to an inefficient supply of the public good, and depending on the nature of the shock (to preferences, technology or income), the distortion can qualitatively differ at the upper and the lower support of the shock such that some regions will over-supply the public good, whereas others will under-supply it.

Our model is also based on asymmetric information between different levels of government, but it differs in important dimensions from the existing literature. On the one hand, our model is simpler because we abstract from interregional insurance by assuming that the central government only cares about the efficient provision of adaptation measures. One way to motivate this is by assuming that a separate redistribution mechanism exists that is independent of regions' adaptation efforts. Because we furthermore focus on unit supply of adaptation measures, we cannot make statements about the intensity of public provision (e.g., in the form of a modified Samuelson rule).

On the other hand, our model is richer in that the regional governments must choose among a set of different adaptation measures that differ with respect to their costs, their effectiveness to prevent damages, and the nature of the associated spillovers. Therefore, local governments have to decide not only upon the level, but also the type of adaptation they want to engage in. To our knowledge, no previous study has formalized the decentralized choice of provision among qualitatively different public goods. A second distinguishing feature of our analysis is the sequential mechanism where regions have to apply for co-funding before receiving it, which is arguably a realistic feature of the interaction between different levels of government, and which introduces the possibility of delayed action.

\footnotetext{
${ }^{6}$ Information asymmetries with spillovers have also been considered by List and Mason (2001) in the context of a stock pollutant, but without a vertical interaction between different levels of government.
} 


\section{The Model}

We consider a setting with three players, who strive to adapt to a new risk imposed by climate change. This risk is modeled by infrequently occurring catastrophic events, for example due to river floods, which have been identified as a key regional climate risk for Europe by the IPCC (2014). Adaptation takes the form of investing in protective measures against these events (e.g., flood walls, retention areas, re-zoning of land). ${ }^{7}$

Two of our players (1 and 2) represent local or regional authorities (referred to as "local players") governing two adjacent regions, and the third player $(G)$ represents the central government. Local authorities aim to minimize the expected costs in their region, which consist of expected damages of extreme events (floods) and adaptation costs (costs of preventive measures). They may receive a co-funding for adaptation from the central government. The central government aims to minimize overall costs, which consist of the costs arising in both regions and the costs of co-funding.

The regions can be of two different types designating low $(L)$ or high $(H)$ vulnerability to extreme events, that is, low or high damages in case of a flood. It is common knowledge that players' types are i.i.d., where $\gamma$ denotes the probability that a region is of type $H$. Depending on the setting, we assume that the actual realizations of players' types are either common knowledge, or are known by the local players but not by the central player.

The occurrence and magnitude of catastrophic floods is uncertain; we assume that there are three different outcomes (zero, low, or high damages), which are the same for both regions. To each of these outcomes, the following probabilities are assigned:

$$
S=\{0, l, h\}, \quad p_{0}+p_{l}+p_{h}=1 .
$$

We consider three different precautionary measures. The first consists of a minor project $m$, which safeguards the region in which it is implemented against a low catastrophic event in the period in which it is implemented. It has no effect against a high-damage event, and it does not cause any spillovers to other regions. An example would be for the

\footnotetext{
${ }^{7}$ The model could easily be applied to other risks imposed by climate change as well.
} 
local government to purchase and store sandbags, such that they are ready to be used in case a minor flood occurs; stapling sandbags does not limit the damage from large floods, however.

In addition, there are two major projects $A$ and $B$, both of which prevent all damages from catastrophic events in the region in which they are implemented for all periods. ${ }^{8}$ However, they differ with respect to their costs and their effect on the other regions. Project $A$ has positive spillovers; it does not only safeguard the region in which it is built, but also completely protects the other region. In contrast, project $B$ has negative spillovers; it prevents damages in the region in which it is built, but increases damages in the other region. An example for project $A$ would be a new water retention area (fields that can be temporarily flooded and thus take water out of the system), whereas a flood wall provides a good example of a project $B .^{9}$

We consider two time periods $T=1,2$, during which the game is played out. Periods are further divided into three consecutive stages: (i) the implementation stage of possible projects (denoted by index $i$ ), (ii) the proposal stage (index $p$ ) and (iii) the central player's decision stage (index $d$ ).

In the implementation stage, players 1 and 2 simultaneously choose among four possible actions: To do nothing (0); implement minor precautionary measures $m$; implement a major project $A$; or implement a major project $B$. Thus, the action space of the implementation stage is given by

$$
\mathcal{A}_{1,2}^{i}=\{0, m, A, B\} .
$$

All players observe the actions taken during the implementation stage, before players 1 and 2 simultaneously decide whether they submit a request for co-funding to the central government during the proposal stage (for the implementation of a major project in the next period). The proposal consists of the type of the major project to be funded ( $A$ or $B$ )

\footnotetext{
${ }^{8}$ Naturally, there may be events of a magnitude that would not be fully contained even by the large measures. We implicitly assume that the likelihood of such super-catastrophic events is small enough, and the cost of prevention measures large enough, such that this risk is accepted as given by all players.

${ }^{9} \mathrm{~A}$ flood wall does not reduce the amount of water in the system but reduces the area that can be flooded. Thus it increases flood events at other locations downriver or, in case a flood wall is only build on one river side, at the other side of the river.
} 
and the proposed cost share to be funded by the central government. The local players can at most submit one project proposal in the proposal stage of each period. In addition, the submission of a proposal entails fixed costs $c$ that are independent of the type of the project. Thus, the action space in this stage of the game is given by:

$$
\mathcal{A}_{1,2}^{p}=\alpha_{1,2} \in[0 ; 1] \times\{A, B\}
$$

with $\alpha_{1,2}$ denoting the requested cost shares. A choice of $\alpha_{i}=0$ indicates that local player $i \in(1,2)$ does not apply for co-funding.

During the decision stage, player $G$ decides about the co-funding applications it has received. The player can choose any co-funding share smaller or equal to the cost share asked in the proposal, including not to support a project proposal at all, such that

$$
\mathcal{A}_{G}^{d}=\alpha_{1,2}^{*} \mid \mathcal{A}_{1,2}^{p} \in[0 ; 1],
$$

with $\alpha_{1,2}^{*} \leq \alpha_{1,2}$. Note that the co-funding shares $\alpha_{i}^{\star}$ decided by player $G$ are earmarked for the proposed projects, but not binding in the sense that a player may implement another project during the implementation stage of period 2 than the project for which he has submitted a proposal in period 1 , although at zero co-funding from player $G$. Finally, the stochastic flood event realizes at the end of the period. ${ }^{10}$

The timing of events implies that co-funded projects can only be implemented in the second period, whereas projects without co-funding could be implemented in either period. This induces a delay in adaptation whenever co-funding is sought for, which is a strong but arguably reasonable assumption as coordination between different levels of government takes time. ${ }^{11}$ Another consequence of the timing in our model is that the second period only consists of an implementation stage (and the realization of the stochastic flood event at the end of the period), as there is no future period and thus proposals do not make sense.

\footnotetext{
${ }^{10}$ We chose not to add a fourth "realization" stage, because there are no interesting actions the players can take. If a flood occurs and a player has chosen option $m$, this option will be implemented.

${ }^{11}$ The time lag in implementation reflects the time needed to plan, secure financing and political support, and build large-scale projects.
} 
The costs of the actions by player 1 and 2 are independent of location and types, and are denoted by $C(0)=0, C(m), C(A)$ and $C(B) .{ }^{12}$ Damage costs from the extreme event depend on the player's type and are denoted by $D_{t}(h)$ and $D_{t}(l)$. We assume the following relationship between these damages:

$$
\begin{aligned}
& D_{t}(h)>D_{t}(l), \quad \forall t \in\{L, H\}, \\
& D_{H}(S)>D_{L}(S), \quad \forall S \in\{l, h\} .
\end{aligned}
$$

If player $i$ implements project $B$, there are negative spillovers to the other player $-i$. In this case, damages are denoted by $D^{+}$with

$$
D_{t}^{+}(S)>D_{t}(S), \quad \forall t \in\{L, H\}, S \in\{l, h\}
$$

If the other player also implements a major project, the damage costs are zero. That is, building a major project protects not only from the extreme event itself, but also from the externalities associated with the action taken by the other player. Finally, all players discount outcomes in period 2 by a discount factor $\delta<1$.

So far, the model covers a large variety of cases, many of which are not interesting, as they lead to rather obvious results. To focus the analysis, we impose the following additional constraints:

1. Projects and player types are relevant:

$$
\begin{aligned}
& p_{l} D_{L}(l)<C(m)<p_{l} D_{L}^{+}(l)<p_{l} D_{H}(l)<p_{l} D_{H}^{+}(l), \\
& (1+\delta)\left[C(m)+p_{h} D_{H}(h)\right]>C(B)>(1+\delta)\left[p_{l} D_{L}(l)+p_{h} D_{L}(h)\right], \\
& C(B)<(1+\delta)\left[C(m)+p_{h} D_{L}^{+}(h)\right], \\
& C(B)>C(m)+p_{h} D_{H}(h)+c .
\end{aligned}
$$

\footnotetext{
${ }^{12}$ It would be straightforward to also allow for asymmetry with respect to the costs of adaptation measures, such that the central government is unsure about the net costs of adaptation.
} 
2. There is a coordination problem:

$$
\begin{aligned}
& C(B)<C(A)<2 C(B), \\
& 2(1+\delta)\left[p_{l} D_{L}(l)+p_{h} D_{L}(h)\right]<C(A), \\
& C(m)+p_{l} D_{L}(l)+p_{h}\left[D_{L}(h)+D_{H}(h)\right]>C(A) .
\end{aligned}
$$

3. Asymmetric information can induce strategic behavior:

$$
c+C(m)-p_{l} D_{L}(l)<\delta\left[p_{l} D_{L}(l)+p_{h} D_{L}(h)\right]
$$

The first set of assumptions implies that the minor project $m$ is always cost-effective for players of type $H$, but is only cost-effective for type $L$ players if the other player has implemented a major project $B$. Furthermore, if the other player does not implement a major project, implementing project $B$ is better for type $H$ players than implementing the minor project $m$, whereas players of type $L$ prefer no precautionary measures over project $B$. In contrast, if the other player implements project $B$, then spillovers increase the damage so strongly that even type $L$ players have an incentive to implement project $B$. Finally, players will never ask for a co-funding of project $B$, as even in case of full funding the costs of delaying implementation are higher than the costs of the project. These assumptions ensure that no project stochastically dominates another. As a consequence, there is indeed a need to choose how to adapt, and the optimal choice will differ among more and less vulnerable regions.

The second set of assumptions implies that we have a coordination problem. The major project $A$ is never individually cost-effective but is socially cost-effective (even when implementation happens in the second period) if and only if at least one player is highly vulnerable. This means that, depending on players' types, there can be a trade-off between what is individually and socially optimal.

The final assumption implies that players of type $L$ have an incentive to mimic players of type $H$ and to propose for and implement a major project $A$, at least if this gets 
fully funded by the central government. Thus, private information can induce strategic behavior.

As a tie-breaking rule, we assume that if player $G$ is indifferent, he will not co-finance the project. Furthermore, if player $G$ is indifferent regarding the funding share, he always pays the full cost share that was demanded by the local player.

\section{Adaptation to Extreme Events in a Federalist State}

In this section, we discuss the equilibria that can arise in our model. We start out by analyzing the benchmarks of pure centralization and pure decentralization, followed by the more realistic situation where governments interact both horizontally and vertically.

\subsection{Benchmark Cases}

We consider three benchmark cases: The social optimum, where the central government has full information, makes all decisions, and minimizes total costs; the fully decentralized solution, where there is no central government and local players decide under full information but without coordination; and the fully centralized solution, where the central government decides alone but without knowing the realized types of the local players.

The following proposition characterizes the outcome in these cases. For ease of exposition, all proofs are collected in the Appendix.

\section{Proposition 1 (Benchmark cases)}

1. In the social optimum

- no player implements a project in any period if they are both of type $L$;

- one player builds project $A$ in the first period (and no other projects are implemented by any player in any period) otherwise.

2. In the fully decentralized solution

- no player implements a project in any period if they are both of type L; 
- both players build projects $B$ in the first period (and no projects in the second period) otherwise.

3. In the fully centralized solution

- project $A$ is implemented whenever the probability that players 1 and 2 are of high damage type $\gamma>\gamma^{0}$, with

$$
\gamma^{0}=\frac{C(A)-2(1+\delta)\left[p_{l} D_{L}(l)+p_{h} D_{L}(h)\right]}{2(1+\delta)\left[p_{l} D_{H}(l)+p_{h} D_{H}(h)\right]-2(1+\delta)\left[p_{l} D_{L}(l)+p_{h} D_{L}(h)\right]} \in(0,1)
$$

- otherwise, no measures are chosen.

Proposition 1 implies that we have to expect welfare losses both in a fully decentralized and in a fully centralized setting. In the decentralized solution, the outcome can be socially optimal only if both players are of type $L$. In the fully centralized solution, the outcome can be socially suboptimal in all cases, depending on the realization of the types of the local players. We discuss the welfare implications in Section 5.

The proposition also suggests that a mix between a centralized solution, which lacks information, and a decentralized approach, which lacks coordination, could potentially lead to a better adaptation to more or more pronounced flood events. In the remainder of this section, we investigate particular combinations of central and decentralized action.

\subsection{Common Aspects under a Federalist Structure}

To solve or mitigate the above problems in a federation, the central government can set incentives to improve upon the decentralized solution via co-funding options, as described above. In our analysis, we consider two cases for this vertical interaction between governments: (i) perfect information and (ii) asymmetric information.

Before discussing these cases in the following subsections, we start by describing an equilibrium that exists in all cases, which allows us to considerably simplify the later analysis: 


\section{Proposition 2 (Only equilibrium involving project $B$ )}

The strategy profile in which players 1 and 2 both implement project $B$ in the implementation stage of the first period, do not submit any proposals and do not implement anything in the second period is a subgame perfect Nash equilibrium. Moreover, this equilibrium is the only equilibrium in which project $B$ is implemented, and it is always socially inefficient.

Due to this result, we can discard action $B$ from the action space of the players without loss of generality. Without $B$, the action space of each player during the implementation stage of period 2 is reduced to $0, m$ and $A$. Furthermore, no major project has already been implemented ( $A$ is never implemented without co-funding and thus never in period 1 ). The expected costs in the second period for player $i$ of type $t_{i}, E C_{t_{i}}^{2}\left(a_{i}, a_{-i}\right)_{\alpha_{i}^{\star}}$, therefore only depend on both players' actions $a_{i}$ and $a_{-i}$ in the second period, and on the cofunding share $\alpha_{i}^{\star}$ offered by player $G$ for implementation of a major project $A$ :

$$
\begin{aligned}
E C_{t_{i}}^{2}(0,0 / m) & =p_{l} D_{t_{i}}(l)+p_{h} D_{t_{i}}(h), \\
E C_{t_{i}}^{2}(m, 0 / m) & =C(m)+p_{h} D_{t_{i}}(h), \\
E C_{t_{i}}^{2}(0, A) & =0 \\
E C_{t_{i}}^{2}(m, A) & =C(m) \\
E C_{t_{i}}^{2}(A, \bullet)_{\alpha_{i}^{\star}} & =C(A)\left(1-\alpha_{i}^{\star}\right) .
\end{aligned}
$$

We first determine the co-funding share $\bar{\alpha}_{t_{i}}$ that player $i$ has to receive in order to be indifferent between implementing the project $A$ or the next best action, assuming that the other player does not implement project $A$. If player $i$ is of type $L$, the second-best action is not to implement anything, whereas players of type $H$ are better off implementing project $m$. Thus, we obtain

$$
\begin{aligned}
& \bar{\alpha}_{L}=1-\frac{p_{l} D_{L}(l)+p_{h} D_{L}(h)}{C(A)} \in(0,1), \\
& \bar{\alpha}_{H}=1-\frac{C(m)+p_{h} D_{H}(h)}{C(A)} \in(0,1) .
\end{aligned}
$$


Assumptions 1-3 outlined above imply that $\bar{\alpha}_{L}>\bar{\alpha}_{H}$, that is, players of type $L$ need a higher co-funding share $\bar{\alpha}_{L}$ to be indifferent between implementing a project $A$ compared to players of type $H$, because they have lower expected damages from the extreme event. This leads to the following Nash equilibria of the subgame starting in the second period:

\section{Proposition 3 (Nash equilibria of the subgame in Period 2)}

In addition to the equilibrium characterized in Proposition 2, the subgame starting in the second period exhibits three different types of equilibria, which depend on the co-funding share $\alpha_{i}^{\star}$ that player $G$ offers for implementing project $A$ in the second period:

1. $\alpha_{i}^{\star} \leq \bar{\alpha}_{t_{i}} \quad \forall i=1,2$ : no player will implement project $A$ and players of type $L$ do nothing and players of type $H$ implement the project $m$.

2. $\alpha_{i}^{\star}>\bar{\alpha}_{t_{i}}$ and $\alpha_{-i}^{\star} \leq \bar{\alpha}_{t_{-i}}$ : player $i$ implements the major project $A$ and player $-i$ does nothing.

3. $\alpha_{i}^{\star}>\bar{\alpha}_{t_{i}} \quad \forall i=1,2$ : in this case there are two equilibria, either player $i$ implements project $A$ and player $-i$ does nothing, or vice versa.

In contrast to the results shown so far, the actions in period 1 hinge on player $G$ 's information about the types of players 1 and 2 . We thus now discuss the cases of perfect and asymmetric information.

\subsection{Perfect Information}

With perfect information, the central government can discern the need for major projects and use co-funding to incentivize the local authorities to implement the socially optimal project. However, this can lead to a situation where local authorities delay adaptation in order to get co-funding. The following proposition characterizes the Nash equilibria that arise under perfect information.

\section{Proposition 4 (Subgame perfect Nash equilibrium under perfect information)}

In addition to the equilibrium characterized in Proposition 2, the game in which players' types are common knowledge exhibits an additional subgame perfect Nash equilibrium: 
1. If both players are of type L: Both players do not implement any project in both periods and do not submit any proposal. Player $G$ rejects any proposal for project $A$.

2. If at least one player is of type $H$ : Player $i$ submits a proposal for project $A$ with funding share $\alpha_{i}=1$, while player $-i$ does not submit a proposal. Player $G$ funds one proposal for project $A$ if submitted, and draws a lot which one to fund in case two proposals are submitted. Player $i$ implements project $A$ in period 2, while player $-i$ does not implement anything in period 2. In period 1, players of type $H$ implement the minor project $m$, and players of type $L$ do nothing.

Because of assumption (7d), both players are better off in the equilibrium of Proposition 4 compared to the equilibrium of Proposition 2. As the local governments determine by their actions in the implementation stage of the first period which of the two equilibria is to emerge, the equilibrium of Proposition 4 is likely to prevail.

\subsection{Asymmetric Information}

Naturally, the case of a perfectly informed central government is of limited interest, as the best alternative could be easily implemented by circumventing the local players. We now turn to the case where the central government (player $G$ ) does not know the type of the two local players, whereas the local players know their own type and the type of the other local player. However, player $G$ knows that players' types are i.i.d., where $\gamma$ denotes the probability of being of type $H$. In the following, we reduce the game to a standard signaling game and discuss the existence of pooling and separating perfect Bayesian Nash equilibria (PBNE).

As the players 1 and 2 are fully symmetric apart from their type, there are three different states of the world that player $G$ has to distinguish. Either both players 1 and 2 are of type $L$, both are of type $H$, or one player is of type $L$ and the other of type $H$. We denote these states by $L L, H H$ and $L H$, respectively.

Due to the fixed costs $c$ of submitting a proposal, and because the local players are indifferent as to which of them implements a fully co-funded project $A$ (project $B$ is ruled 
out by Proposition 2), at most one player will submit a proposal. Furthermore, it is not important for player $G$ to discern the individual players' types, as $G$ will only co-fund one proposal, and the location of $A$ is irrelevant. We can therefore pool players 1 and 2 to be a "joint" sender of a signal, which is received by player $G$. We can differentiate four possible actions/signals for the joint sender: $N$ (no proposal), $P$ (proposal, no minor projects), $m P$ (proposal, one minor project) and $m m P$ (proposal with two minor projects).

If a proposal is submitted, player $G$ has two possible actions: Either to co-fund a proposal $(f)$ or not to co-fund it $(n)$. Our assumptions imply that player $G$ will only cofund a project if at least one player is of type $H .^{13}$ Such a player will always implement a minor project in the implementation stage of period 1 , so that $G$ will never co-fund a proposal if he observes $P .{ }^{14}$ Consequently, the action $P$ of the sender is always strictly dominated and thus does not has to be considered further.

The remaining game is a signaling game with three types $(L L, L H$, and $H H)$, three possible messages $(N, m P$, and $m m P$ ) and two feasible receiver actions ( $f$ and $n$ ), as illustrated in Figure 1. The receiver's beliefs for being in the upper information set are denoted by $p^{H H}, p^{L H}$ and $1-p$ with $p=p^{L H}+p^{H H}$, and for being in the lower information set by $q^{H H}, q^{L H}$ and $1-q$ with $q=q^{L H}+q^{H H}$. This game has three different classes of perfect Bayesian Nash equilibria, which are explicitly derived in the Appendix and summarized in the following proposition.

\section{Proposition 5 (Perfect Bayesian Nash equilibrium, asymmetric information)}

In addition to the equilibrium characterized in Proposition 2, the game in which the type of players 1 and 2 are not known to player G exhibits three additional perfect Bayesian Nash equilibria:

\footnotetext{
${ }^{13}$ Furthermore, player $G$ will only co-fund a proposal for project $A$, if the player submitting this proposal itself has implemented a minor project. This rules out cases, where senders of type $L L$ "share costs" of mimicking senders of type $L H$ in the sense that one player implements project $m$ while the other submits a proposal for project $A$. Ruling out such collusion increases the costs for $L L$ senders of mimicking senders of type $L H$ without any additional consequences for player $G$ and is thus clearly in the interest of player $G$.

${ }^{14}$ Note that senders of type $L H$ and $H H$ never have an incentive to mimic senders of type $L L$, so that player $G$ does not have to take into account the possibility that no minor projects are implemented to mimic a low-type sender.
} 
1. A separating equilibrium, in which senders of type $L L$ do not implement any minor projects in both periods and do not submit a proposal, senders of type LH implement one minor project $m$ in the first period, submit a proposal for project $A$ with funding share $\alpha_{i}=\alpha_{L L}-\epsilon$ which is funded and implemented, and senders of type $H \mathrm{H}$ implement two minor projects $m$ in the first period, submit a proposal for project $A$ with funding share $\alpha_{i}=\alpha_{L L}-\epsilon$ which is funded and implemented, where $\alpha_{L L}$ is given by

$$
\bar{\alpha}_{L L}=1-\frac{\delta\left[p_{l} D_{L}(l)+p_{h} D_{L}(h)\right]-\left[C(m)-p_{l} D_{L}(l)\right]-c}{\delta C(A)},
$$

and $\epsilon>0$ is arbitrarily small.

2. A semi-separating equilibrium that exists for $\gamma>\bar{\gamma}$ with

$$
\bar{\gamma}=\frac{C(A)-2\left[p_{l} D_{L}(l)+p_{h} D_{L}(h)\right]}{2\left[C(m)+p_{h} D_{H}(h)\right]-C(A)},
$$

in which senders of type $L L$ and type $L H$ implement one minor project $m$ in the first period, submit a proposal for project $A$ with funding share $\alpha_{i}=1$ that is funded and implemented, and senders of type $H H$ implement two minor projects $m$ in the first period, submit a proposal for project $A$ with funding share $\alpha_{i}=1$ that is funded and implemented.

3. A pooling equilibrium that exists for $\gamma<\gamma \leq \bar{\gamma}$ with

$$
\underline{\gamma}=\frac{C(A)-2\left[p_{l} D_{L}(l)+p_{h} D_{L}(h)\right]}{2\left[C(m)+p_{h} D_{H}(h)\right]-2\left[p_{l} D_{L}(l)+p_{h} D_{L}(h)\right]},
$$

in which senders of all types implement two minor projects $m$ in the first period, submit a proposal for project $A$ with funding share $\alpha_{i}=1$ that is funded and implemented.

From a social perspective, the separating PBNE is identical to the subgame perfect Nash equilibrium under perfect information (Proposition 4). In fact, for small values of $\gamma$ (i.e., $\gamma \leq \underline{\gamma}$ ) this is the only PBNE. Thus, information asymmetry does not worsen the situation compared to the perfect information case. 


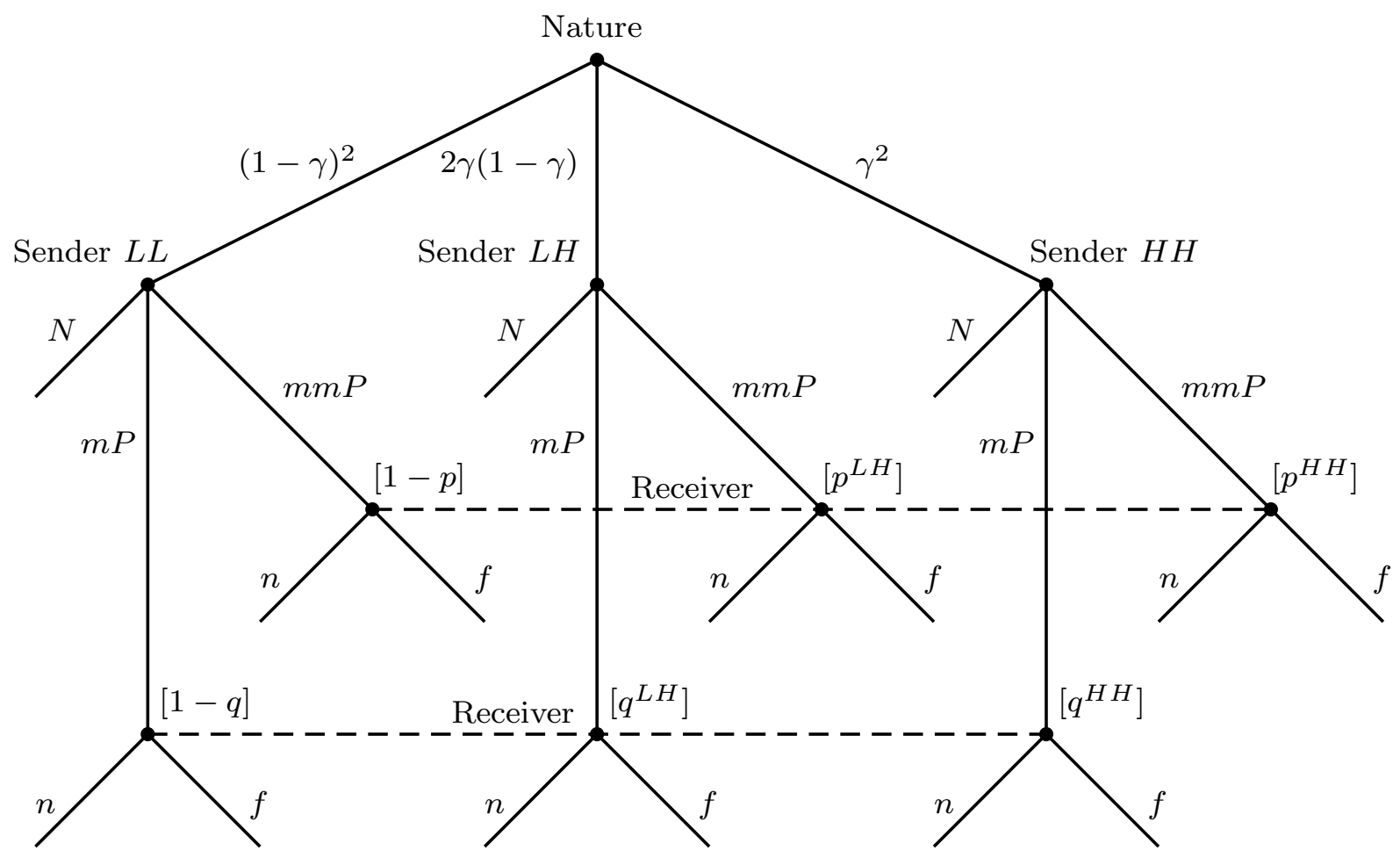

Figure 1: Extensive form of the simplified signalling game: Symmetric case

However, in case of high values of $\gamma$ (i.e., $\gamma>\bar{\gamma}$ ) there exists also a semi-separating equilibrium that is preferred by all types of senders and, thus, is likely to prevail. This equilibrium exhibits two additional inefficiencies: First, project $A$ is implemented even if both players are of type $L$. Second, in order to mimic players of type $H$, an inefficient minor project $m$ is implemented.

For intermediate values of $\gamma$ (i.e., $\underline{\gamma}<\gamma \leq \bar{\gamma}$ ), there exists a pooling equilibrium in addition to the separating equilibrium. Senders of type $L L$ and type $H H$ prefer the pooling equilibrium, whereas in the case of sender type $L H$ one player is better off with the pooling, the other player with the separating equilibrium. As a consequence, we cannot rule out that the more inefficient pooling equilibrium is played. The pooling equilibrium exhibits an additional inefficiency over the semi-separating equilibrium: all sender types implement two minor projects $m$ which is inefficient in case of type $L L$ and $L H$ senders. This result is qualitatively similar to those in Besfamille (2003), who also finds that asymmetric information leads to over-spending on local public projects. 
Overall, we again have the problem of delayed implementation. In addition, there is a risk of strategic mimicking: A player might behave as if he were to benefit from a major project and thus induce an inefficient investment by the central player. However, in our simple model framework player $G$ can safeguard himself against the semi-separating and the pooling equilibrium by restricting the co-funding share to $\alpha^{\max }=\alpha_{L L}-\epsilon$. In this case players of type $L L$ never have an incentive to apply for co-funding, which eliminates the semi-separating and pooling equilibrium while the separating equilibrium survives.

\section{Welfare Analysis}

In Section 4.4, we show that the federalist regime is able to elicit the private information of player types by setting an appropriate upper bound for the co-funding share $\alpha$. However, learning the players' types comes at the cost of delayed implementation. Now we turn to the question whether and under what conditions the federalist regime is preferable to the two benchmarks of a fully decentralized and a fully centralized policy regime. To this end, we calculate the expected welfare loss of the different regimes compared to the social optimum as a function of the a priori probability $\gamma$ that a player $i(i=1,2)$ is of type $H$.

In the fully decentralized solution, the social optimum is achieved if both players are of type $L$. In any other case both players implement a major project $B$ while building one major project $A$ would be socially optimal. As a consequence, the expected welfare loss reads:

$$
\Delta E C^{D}(\gamma)=\gamma(2-\gamma)[2 C(B)-C(A)]
$$

For $\gamma=0$ the expected welfare loss equals zero and increases quadratically in $\gamma$ to reach its maximum of $2 C(B)-C(A)$ for $\gamma=1$. Thus, the decentralized regime performs worse the higher is the a priori probability $\gamma$ that players 1 and 2 are of type $H$.

In the fully centralized policy regime a major project $A$ is implemented whenever $\gamma>\gamma^{0}$ and nothing is undertaken otherwise. Thus, we obtain for the expected welfare 
loss:

$$
\Delta E C^{C}(\gamma)=\left\{\begin{array}{cc}
2(1+\delta) \gamma\left\{p_{l} D_{H}(l)+p_{h} D_{H}(h)+(1-\gamma)\left[p_{l} D_{L}(l)+p_{h} D_{L}(h)\right]\right\} & \\
-\gamma(2-\gamma) C(A) & \gamma \leq \gamma^{0} \\
(1-\gamma)^{2}\left\{C(A)-2(1+\delta)\left[p_{l} D_{L}(l)+p_{h} D_{L}(h)\right]\right\}, & \gamma>\gamma^{0}
\end{array}\right.
$$

Thus, the expected welfare loss starts at zero for $\gamma=0$ and increases until $\gamma=\gamma^{0}$, where it reaches its maximum of

$$
\Delta E C^{C}\left(\gamma^{0}\right)=\frac{\left[C(A)-2(1+\delta)\left(p_{l} D_{H}(l)+p_{h} D_{H}(h)\right)\right]^{2}\left[C(A)-2(1+\delta)\left(p_{l} D_{L}(l)+p_{h} D_{L}(h)\right)\right]}{4(1+\delta)^{2}\left[p_{l}\left(D_{H}(l)-D_{L}(l)\right)+p_{h}\left(D_{H}(h)-D_{l}(h)\right)\right]^{2}},
$$

and decreases for $\gamma>\gamma^{0}$ to reach zero at $\gamma=1$. As a consequence, the centralized policy regime performs well for very low and very high values of $\gamma$ but worse in the intermediate cases, in particular around $\gamma^{0}$.

We know turn to the expected welfare loss in our federalist policy regime. Recall that for all values of $\gamma$ there exists a separating perfect Bayesian Nash equilibrium which, from a social welfare perspective, is equivalent to the subgame perfect Nash equilibrium under perfect information. There exist two other perfect Bayesian Nash equilibria in the federalist policy regime: A pooling equilibrium for $\underline{\gamma}<\gamma \leq \bar{\gamma}$ and a semi-separating equilibrium for $\gamma>\bar{\gamma}$. With respect to expected welfare loss these equilibria are worse than the separating equilibrium. This holds particularly for the pooling equilibrium. However, in our simple model framework player $G$ can safeguard himself against the semi-separating and the pooling equilibrium by setting an upper bound for the co-funding share $\alpha^{\max }<1$, as discussed in Section 4.4. As a consequence, we restrict attention to the separating equilibrium. In this equilibrium players of type $L L$ do nothing, which is also socially optimal. In all other cases players of type $H$ implement a minor project $m$ in the first period and one player asks for funding of a major project $A$, which is approved by player $G$ and implemented in the second period. While the right project is implemented this occurs with a delay. In addition, there is a welfare cost due to the fixed submission cost $c$. Thus, the 
expected welfare loss reads:

$$
\begin{gathered}
\Delta E C^{\text {sep }}(\gamma)=\gamma\left\{2\left[C(m)+p_{h} D_{H}(h)+(1-\gamma)\left(p_{l} D_{L}(l)+p_{h} D_{L}(h)\right)\right]\right. \\
+(2-\gamma)[C(A)(\delta-1)+c]\} .
\end{gathered}
$$

Like in the case of the decentralized regime the expected welfare loss is zero for $\gamma=0$ and is increasing in $\gamma$ to reach

$$
\Delta E C^{s e p}(1)=2\left[C(m)+p_{h} D_{H}(h)\right]+(\delta-1) C(A)+c,
$$

at $\gamma=1$.

The following proposition states the results for the welfare comparison of the different regimes:

\section{Proposition 6 (Welfare Analysis)}

For the expected welfare loss the following statements hold:

1. For sufficiently high values of $\gamma$ the fully centralized regime outperforms the fully decentralized and the federalist regime.

2. For sufficiently small values of $\gamma$ and a sufficiently small submission fee $c \leq p_{l} D_{H}(l)-$ $C(m)$ the federalist regime outperforms the fully centralized regime.

3. If $2 C(B)>E C_{H H}$ with

$$
E C_{H H}=2\left[C(m)+p_{h} D_{H}(h)\right]+c+\delta C(A),
$$

then the federalist regime outperforms the fully decentralized regime.

If $2 C(B)<E C_{L H}$ with

$$
E C_{L H}=C(m)+p_{l} D_{L}(h)+p_{h}\left[D_{L}(h)+D_{H}(h)\right]+c+\delta C(A),
$$


then the fully decentralized regime outperforms the federalist regime.

If $2 C(B)>E C_{L H}$ and $2 C(B)<E C_{H H}$ then the federalist regime exhibits a lower (higher) expected welfare loss for small (high) values of $\gamma$.

The first part of Proposition 6 says that the fully decentralized regime is always the best regime if $\gamma$ is sufficiently high. The intuition is that if $\gamma$ is very high, there is hardly any uncertainty (both players are almost sure of type $H$ ). In this case, a benevolent central player can easily choose the first best option - implementing a major project $A$ in the first period - which is not implemented in the fully decentralized and the federalist regime.

The second part of the proposition states that this reasoning is not true for the case of very small $\gamma$. In this case the social planner in the fully centralized regime cannot learn the types of the players while in the federalist regime player types are identified. As a consequence, for any $\gamma \in\left[0, \gamma^{0}\right]$ there is the risk that at least one player is of type $H$, yet the social planner does not implement anything. Due to assumption (8c) a delayed implementation of the major project $A$ is better than doing nothing if at least one player is of type $H$ and proposal submission costs $c$ are sufficiently small.

Whether the fully decentralized or the federalist regime perform better depends on how the welfare loss of an "arms race" (i.e., implementing two major projects $B$ ) compares to the welfare loss due to the delayed implementation of the major project $A$ in case that at least one player is of type $H$.

In summary, if the welfare loss of the federalist regime is small compared to the welfare loss in the fully decentralized solution, i.e. the proposal submission costs are low and the delay in implementing the project $A$, whenever this is optimal, is small, then the federalist regime is the best regime for sufficiently small values of $\gamma$. Yet, the fully centralized regime always performs best for sufficiently high values of $\gamma$.

\section{Robustness of results and extensions}

Above, we show in a parsimonious two-period setting with one central and two local players that efficient adaptation is difficult to achieve if crucial information for optimal 
adaptation is private to the local authorities. In the following, we argue that our results are robust to changes along several dimensions.

First, the model can be extended to any number $N$ of local players in a straightforward manner. Assuming again that players' types are i.i.d with $\gamma$ being the probability that a local player is of type $H$, expected welfare losses under the different regimes crucially depend on how many players have to be of type $H$ for the project $A$ to be socially optimal. In general, more players render the arms race under the fully decentralized regime increasingly costly and, thus, making it more likely that the federalist regime performs better. Also the result that the centralized regime is always best for sufficiently high $\gamma$ is robust to an increase in the number of players.

Second, our model is robust to the number of available projects, as long as these projects can be ranked with respect to the protection against extreme events that they offer, their scope and type of externalities they impose on other players, and their costs of implementation. As the set of different projects increases, the federalist regime becomes more likely to dominate the fully centralized. The underlying intuition is that with a wider variety of available projects to choose from, learning the players' types becomes increasingly important to implement the least costly adaptation measures.

Finally, our two period set-up can be easily extended to an infinite time horizon, as long as the probabilities associated with the different extreme events are constant over time. Players in the fully decentralized regime implement a project $B$ (if at all) in the first period. The central player in the fully decentralized regime has an incentive to implement the project $A$ in the first period regardless of the number of periods since he already knows the probabilities of the extreme events and he cannot learn about players' types by waiting another period. In the signaling game of the federalist regime, the central player learns the players' types in the first round and co-funds proposals for a major project $A$ accordingly, which are then implemented in the second period. Again, there is nothing to be gained by postponing implementation to a third or fourth round.

If, however, the probabilities for the occurrence of the extreme events change over time, the timing of implementation might change even in the case of full information. 
Increasing the number of periods to $T>2$ introduces the option to wait, since it could be optimal to implement a major project only once the probabilities of extreme events reach a certain threshold value. We also abstract from the value of learning, whereas the central player as well as local ones may choose to wait with the implementation of projects until they learn more about the true probabilities associated with extreme events.

As a consequence, allowing for changing probabilities of the extreme events requires a more involved analysis of the underlying probabilistic structure, which we leave for future research. Other possible extensions include allowing for a mobile population which would make the damages endogenous, and the financing of measures by means of nonbenefit taxation.

\section{Conclusions}

In the absence of sufficiently effective mitigation policies, adaptation to climate change has become an interesting and perhaps even necessary substitute or complement to mitigation. Adaptation is typically assumed to be a much simpler problem than mitigation, as many adaptation measures constitute at most regional public goods and thus do not require complex international negotiations. If an efficient adaptation is possible, it might help to reduce the costs incurred by delayed mitigation.

In this paper, we investigate the options for implementing local adaptation measures using the example of adapting to more extreme flood events. Using a simple theoretical model, we show that we should not expect that efficient adaptation outcomes can be achieved without specific supporting policies. In all settings that we considered (a centralized and a decentralized solution as well as a decentralized solution with a central funding scheme for coordination), there is a substantial risk of inefficient outcomes.

This risk stems from two sources. First, without central oversight, local adaptation measures are likely to be inefficient if they cause positive or negative spillovers between regions. Second, central coordination will often cause delays, and central authorities are likely to depend on local authorities for site-specific information. This information 
asymmetry can easily result in inefficient spending on too large adaptation projects, as local authorities will exploit their informational advantage.

However, the federalist regime allows the central government to perfectly learn the players' types within the first period by choosing an appropriate maximal co-funding share $\alpha^{\max }<1$. As a consequence, the performance of the federalist regime compared to the fully decentralized and fully centralized regime strongly depends on how costly it is to apply for co-funding (submission costs $c$ ) and how long is the time delay for the implementation of a co-funded project.

These results already appear in a simple three-player setting with three possible adaptation measures and two types of players. We also abstract from mobile factors of production and tax competition between regions. Many real-world settings are much more complex and thus more prone to the exploitation of strategic advantages, delays, and suboptimal choices of adaptation measures. Our results are fundamentally driven by the assumptions that adaptation requires local knowledge, and that some adaptation measures can cause externalities to other locations. These aspects are also likely to be present in the contexts of adaptation to droughts, desertification, or sea-level rise.

Our analysis does not imply that adaptation is not useful, but that we should not simply assume in assessments of climate policies that adaptation will occur timely and efficiently. We show that adaptation is a rather complex public goods problem, and most societies do not excel in solving such problems. If we want or have to adapt to climate change, we will need more research on which policies might facilitate different types of adaptation. Last but not least, we should be aware that actual adaptation decisions might be highly inefficient and thus more costly. Consequently, adaptation is a less promising substitute for mitigation than it appears to be if it is simply assumed to be optimal. 


\section{Appendix}

\section{A.1 Proof of Proposition 1}

Regarding the social optimum, our assumptions imply that whenever one local player is of type $H$, project $A$ should be implemented in the first period. The location is irrelevant, as it protects both regions. If both players are of type $L$, the social optimum consists in both players not implementing anything in both periods.

In the case without a central government, a local player of type $H$ will always build project $B$ in the first period, and the other player will respond by also building $B$ in the first period, regardless of his type. This is always a Nash equilibrium, even if both players are of type $L$. However, if both players are of type $L$, there is an additional Nash equilibrium, in which both players do nothing in both periods. Because this equilibrium Pareto-dominates the equilibrium in which both players build project $B$ in the first period, we assume that this equilibrium prevails.

Finally, consider the fully centralized solution. The central government would like to implement project $A$ whenever at least one local player is of type $H$, and do nothing otherwise. However, the central government does not know the type of the local players. Assuming that the type of both players is drawn independently from the same distribution and that the probability of being of type $H$ is $\gamma$, the expected cost difference for the central government between implementing project A and doing nothing is given by:

$$
\begin{aligned}
\Delta E C_{G}^{0}= & (1-\gamma)^{2}\left\{C(A)-2(1+\delta)\left[p_{l} D_{L}(l)+p_{h} D_{L}(h)\right]\right\} \\
& +2 \gamma(1-\gamma)\left\{C(A)-(1+\delta)\left[p_{l}\left(D_{L}(l)+D_{H}(l)\right)+p_{h}\left(D_{L}(h)+D_{H}(h)\right)\right]\right\} \\
& +\gamma^{2}\left\{C(A)-2(1+\delta)\left[p_{l} D_{H}(l)+p_{h} D_{H}(h)\right]\right\} \\
= & C(A)-2(1+\delta)\left[p_{l} D_{L}(l)+p_{h} D_{L}(h)\right] \\
& -2(1+\delta)\left[p_{l}\left(D_{H}(l)-D_{L}(l)\right)+p_{h}\left(D_{H}(h)-D_{L}(h)\right)\right] .
\end{aligned}
$$

$\Delta E C_{G}^{0}<$ and, thus, the central government would implement project $A$, whenever $\gamma>\gamma^{0}$ where $\gamma^{0}$ is given by Eq. (10). Note that our assumptions (7a),(8b), and (8c) imply 
$\gamma^{0} \in(0,1)$. A central government that does not know the types of the local players would thus implement the wrong policy with a probability of $(1-\gamma)^{2}$ if $\gamma>\gamma^{0}$, and with a probability of $1-p_{L}^{2}$ otherwise.

\section{A.2 Proof of Proposition 2}

Due to assumption (7d) players 1 and 2 will never ask for co-funding of a project $B$ and player $G$ would never co-fund a project $B$ if it was proposed. Together with the perfect information of local players, this implies that the players 1 and 2 either implement project $B$ in period 1 or never.

In addition, player $G$ will never co-fund a proposal for project $A$ if there is already a project $B$ in place. ${ }^{15}$ Consequently, if one player implements $B$ in the first period, the other player will not apply for $A$.

Finally, given our assumptions, the best response to the implementation of project $B$ in the first period is also to implement a project $B$. As a consequence, implementing project $B$ in the first period by both players is a subgame perfect Nash equilibrium. Thus if $B$ is implemented at all, it is always implemented by both players in the first period. Furthermore, this equilibrium is always inefficient (see Proposition 1).

\section{A.3 Proof of Proposition 4}

The types of players 1 and 2 are common knowledge. If both players are of type $L$, player $G$ will not co-fund a major project. Anticipating this, players will not submit any proposals. In addition, both players will not implement any project in the first and second period.

If at least one player is of type $H$, it is socially optimal to implement a major project $A$ by player 1 or 2 . Player $G$ will always fund one project $A$ in case that at least one project $A$ proposal is submitted. If two project $A$ proposal are submitted, player $G$ is indifferent and randomly chooses to support one of the projects. However, both local players submitting a

\footnotetext{
${ }^{15}$ As $B$ already exists, one player is fully protected against damages and thus $A$ is not cost-efficient anymore.
} 
project $A$ proposal cannot be an equilibrium: If player $i$ submits a project $A$ proposal (that subsequently will be supported by player $G$ and also implemented) the best response of player $-i$ is not to submit a proposal due to the submission costs $c$.

Furthermore, as there are no signaling incentives among players (due to full information), players ask for cost share $\alpha_{i}=1$, that is, the major project $A$ is always fully funded by the central government. According to our assumptions, the central government will agree to pay for the full costs of project $A$, if it approves of the project in the first place.

This means that there are two equilibrium outcomes in pure strategies. Either player 1 proposes a major project $A$ with full funding $\alpha_{1}=1$, gets the project approved and finally implements project $A$, while player 2 does not submit a proposal, and vice versa. In addition, players of type $L$ will not implement anything in the first period, while players of type $H$ implement the minor project $m$.

\section{A.4 Proof of Proposition 5}

We first consider separating equilibria. With our three types of senders and the three different signals, there are six different separating sender strategies: ${ }^{16}(N, m P, m m P)$, $(m P, N, m m P),(m P, m m P, N),(N, m m P, m P),(m m P, N, m P)$ and $(m m P, m P, N)$. As the receiver learns the type of the sender in a separating equilibrium and player $G$ is not willing to fund the project $A$ in case both players are of type $L$, senders of type $L L$ have an incentive to switch to action $N$. This eliminates the second, third, fifth and sixth strategy. In addition, $(N, m m P, m P)$ cannot be an equilibrium strategy as senders of type $L H$ have an incentive to switch to $m P$ and senders of type $H H$ prefer $m m P$ over $m P$.

Thus, the only candidate for a separating equilibrium is the sender strategy $(N, m P, m m P)$. The only consistent belief the receiver can hold given this sender strategy is $p^{H H}=1$ and $q^{L H}=1$, implying $p^{L H}=0$ and $q^{H H}=0$. By assumption and given these beliefs, the

\footnotetext{
${ }^{16}$ In the following, we denote a sender strategy by a triple of actions where the first action indicates the action played by type $L L$ senders, the second action belongs to type $L H$ senders and the third to senders of type $H H$. For example, $(N, m P, m m P)$ denotes the sender strategy in which $L L$ senders play $N$, senders of type $L H$ play $m P$ and senders of type $H H$ choose action $m m P$. If we also want to pin down the funding shares, we employ the notation $\left(a_{L L}, \alpha_{L L} ; a_{L H}, \alpha_{L H} ; a_{H H}, \alpha_{H H}\right)$, where $a_{i}$ are the actions of senders of different types and $\alpha_{i}$ denote the proposed funding shares (if applicable).
} 
receiver funds project $A$ upon observing message $m P$ and $m m P .{ }^{17}$ Thus, the receiver's best response is $(f, f)$, such that senders of type $L H$ and $H H$ have no incentive to deviate from $m P$ and $m m P$, respectively, as long as the funding share $\alpha_{i}>\bar{\alpha}_{L H}=\bar{\alpha}_{H H}$ with

$$
\bar{\alpha}_{L H}=\bar{\alpha}_{H H}=1-\frac{\delta\left[C(m)+p_{h} D_{H}(h)\right]-c}{\delta C(A)} .
$$

However, senders of type $L L$ might have an incentive to switch from $N$ to $m P$ or $m m P$, depending on the funding share. Senders of type $L L$ play $m P$ or $m m P$ instead of $N$ if $\alpha_{i}>\bar{\alpha}_{L L}$ with:

$$
\bar{\alpha}_{L L}=1-\frac{\delta\left[p_{l} D_{L}(l)+p_{h} D_{L}(h)\right]-\left[C(m)-p_{l} D_{L}(l)\right]-c}{\delta C(A)} .
$$

Under our assumptions, we always have $\bar{\alpha}_{L L}>\bar{\alpha}_{L H}=\bar{\alpha}_{L H}$. Thus, there exists a separating perfect Bayesian Nash equilibrium (PBNE), in which senders of type $L L$ play $N$, whereas senders of type $L H$ and type $H H$ play $m P$ and $m m P$ with a funding share $\alpha_{i}=\alpha_{L L}-\epsilon$ with some arbitrarily small $\epsilon>0$. Formally, the strategies and beliefs

$$
\left[\left(N ; m P, \alpha_{L L}-\epsilon ; m m P, \alpha_{L L}-\epsilon\right),(f, f), p^{H H}=q^{L H}=1, p^{L H}=q^{H H}=0\right]
$$

constitute a separating PBNE.

We now consider pooling equilibria. Here, $G$ cannot induce the sender's type from its actions before deciding upon co-funding. There are three possible pooling equilibria. Either all types of senders do not submit a proposal, $(N, N, N)$, implement one minor project $m$ and submit a proposal for project $A,(m P, m P, m P)$, or implement two projects $m$ and submit a proposal, $(m m P, m m P, m m P)$.

We start with $(N, N, N)$. Imposing the intuitive criterion (Cho and Kreps, 1987), this cannot be an equilibrium strategy. To see this, consider the action $m m P$ with an $\alpha_{i}=$ $\alpha_{L L}-\epsilon$. This strategy is equilibrium-dominated for senders of type $L L$, i.e. senders of

\footnotetext{
${ }^{17}$ In the following, we denote the receivers strategy by a tuple of actions, where the first action denotes the action the receiver plays upon observing the message $m P$ and the second action is the action played after receiving message $m m P$. For example $(n, f)$ denotes the receiver's strategy in which $n$ is played upon observing $m P$ and $f$ is played after receiving $m m P$.
} 
type $L L$ never have an incentive to play this action instead of the equilibrium action $N$. In contrast, it is not equilibrium-dominated by senders of type $L H$ and $H H$. Thus, the only consistent belief the receiver can hold after observing $m m P$ is that $p=1$. Given this belief, the best response to the action $m m P$ is to fund the project $A$. But conditional on this strategy of the receiver, senders of type $L H$ and $H H$ have an incentive to deviate from the strategy $(N, N, N)$ and, thus, $(N, N, N)$ cannot be an equilibrium.

Let us now consider $(m P, m P, m P)$ and $(m m P, m m P, m m P)$. Given these strategies, the receiver does not learn anything above the a priori probability distribution of sender types. As a consequence, the only consistent beliefs of the receiver are $q^{L H}=2 \gamma(1-\gamma)$, $q^{H H}=\gamma^{2}$ and no restrictions on $p^{L H}$ and $p^{H H}$ in case of strategy $(m P, m P, m P)$, and $p^{L H}=$ $2 \gamma(1-\gamma), p^{H H}=\gamma^{2}$ and no restrictions on $q^{L H}$ and $q^{H H}$ for strategy $(m m P, m m P, m m P)$. Whether senders have an incentive to deviate from this strategy depends on the receiver's best response. The difference in expected second period costs for player $G$ between funding and not funding a project $A$ are given by

$$
\begin{aligned}
& \Delta E C_{G}=(1-\gamma)^{2}\left\{C(A)-2\left[p_{l} D_{L}(l)+p_{h} D_{L}(h)\right]\right\} \\
& \quad+2 \gamma(1-\gamma)\left\{C(A)-C(m)-p_{l} D_{L}(l)-p_{h}\left[D_{L}(h)+D_{H}(h)\right]\right\} \\
& \quad+\gamma^{2}\left\{C(A)-2\left[C(m)+p_{h} D_{H}(h)\right]\right\} .
\end{aligned}
$$

Under our assumptions, the first line is positive, whereas the second and third lines are negative. Thus, player $G$ 's best response is to co-fund $A$ if $\gamma$ is sufficiently high. We denote the value for which $\Delta E C_{G}=0$ by $\underline{\gamma}$ (see Eq. (15)). Then, strategies $(m P, m P, m P)$ and $(m m P, m m P, m m P)$ can only be equilibrium strategies if $\gamma>\underline{\gamma}$. However, employing the intuitive criterion, $(m P, m P, m P)$ cannot be an equilibrium strategy, because the action $m m P$ is equilibrium dominated for senders of type $L L$ and type $L H$ but not for senders of type $H H$. Thus, the only consistent belief is $q^{H H}=1$. In this case, the receiver's best response to $m m P$ is $f$ and, therefore, senders of type $H H$ have an incentive to play action $m m P$ instead of $m P$.

We now examine whether senders of type $L L$ and $L H$ also have an incentive to deviate from $(m m P, m m P, m m P)$ and play $m P$ instead. As $m P$ is equilibrium dominated for 
senders of type $H H$ but not for senders of type $L L$ and $L H$, the intuitive criterion restricts the receiver's beliefs to $q^{H H}=0$ but does not impose any restriction on $q^{L H}$. However, as both types of players benefit equally from a deviation to $m P$ given the receiver funds the proposal, the receiver considers it to be equally likely that a player of type $L L$ plays $m P$ as a player of type $L H$. The receiver's belief is thus given by $q^{L H}=2 \gamma(1-\gamma) /\left[(1-\gamma)^{2}+\right.$ $2 \gamma(1-\gamma)]$. The expected cost difference for the receiver between funding and not funding a project upon receiving $m P$ is

$$
\begin{aligned}
& \Delta E C_{G}^{L L, L H}=\frac{(1-\gamma)^{2}}{(1-\gamma)^{2}+2 \gamma(1-\gamma)}\left\{C(A)-2\left[p_{l} D_{L}(l)+p_{h} D_{L}(h)\right]\right\} \\
& \quad+\frac{2 \gamma(1-\gamma)}{(1-\gamma)^{2}+2 \gamma(1-\gamma)}\left\{C(A)-C(m)-p_{l} D_{L}(l)-p_{h}\left[D_{L}(h)+D_{H}(h)\right]\right\}
\end{aligned}
$$

Let $\bar{\gamma}$ be the value of $\gamma$ such that $\Delta E C_{G}^{L L, L H}=0$ and which is given by Eq. (14). It is then optimal for the receiver to play $n$ when observing the message $m P$ if $\gamma \leq \bar{\gamma}$. If the receiver does not fund the project in case of observing $m P$, senders of type $L L$ and $L H$ have no incentive to deviate from the strategy $(m m P, m m P, m m P)$. Thus, there exists a pooling PBNE for $\underline{\gamma}<\gamma \leq \bar{\gamma}$ :

$$
\begin{aligned}
& {\left[(m m P, 1 ; m m P, 1 ; m m P, 1),(n, f), p^{L H}=2 \gamma(1-\gamma), p^{H H}=\gamma^{2},\right.} \\
& \left.q^{L H}=\frac{2 \gamma(1-\gamma)}{(1-\gamma)^{2}+2 \gamma(1-\gamma)}, q^{H H}=0\right] .
\end{aligned}
$$

Finally, there are 18 semi-separating strategies, in which senders of two different types send the same message, while the remaining sender type sends a different message. As a consequence, the receiver can partly infer sender types from the observed messages. However, most of these 18 strategies cannot be equilibrium strategies. In fact, the only strategy for which it is not immediately obvious that at least one type of senders is better off deviating is the strategy $(m P, m P, m m P)$.

Given strategy $(m P, m P, m m P)$, the receiver's beliefs are restricted to $p^{H H}=1, p^{L H}=$ $0, q^{H H}=0$ and $q^{L H}=2 \gamma(1-\gamma) /\left[(1-\gamma)^{2}+2 \gamma(1-\gamma)\right]$. Given these beliefs, the receiver's best respond to $m m P$ is $f$. It's best response to $m P$ is also $f$ if $\Delta E C_{G}^{L L, L H}<0$ (see Eq. (A.6)) implying $\gamma>\bar{\gamma}$. Thus, if $\gamma>\bar{\gamma}$, no sender type has an incentive to deviate. As a 
consequence, we find the following semi-separating PBNE for $\gamma>\bar{\gamma}$ :

$$
\begin{aligned}
& {\left[(m P, 1 ; m P, 1 ; m m P, 1),(f, f), p^{L H}=0, p^{H H}=1,\right.} \\
& \left.q^{L H}=\frac{2 \gamma(1-\gamma)}{(1-\gamma)^{2}+2 \gamma(1-\gamma)}, q^{H H}=0\right] .
\end{aligned}
$$

\section{A.5 Proof of Proposition 6}

The first part follows directly from the fact that the welfare loss for the fully centralized regime converges to zero for $\gamma \rightarrow 1$, while it converges to strictly positive values for the fully decentraliced and the federalist regime.

To see the second part, we take the first derivatives of the expected welfare losses under the fully centralized and the federalist regime and evaluate them at $\gamma=0$ :

$$
\begin{aligned}
& \left.\frac{d \Delta E C^{C}(\gamma)}{d \gamma}\right|_{\gamma=0}=2(1+\delta)\left\{p_{l}\left[D_{L}(l)+D_{H}(l)\right]+p_{h}\left[D_{L}(h)+D_{H}(h)\right]\right\}-2 C(A), \quad \text { A.9a) } \\
& \left.\frac{d \Delta E C^{s e p}(\gamma)}{d \gamma}\right|_{\gamma=0}=2\left\{C(m)+p_{l} D_{L}(l)+p_{h}\left[D_{L}(h)+D_{H}(h)\right]+c+\delta C(A)\right\}-2 C(A) .
\end{aligned}
$$

Thus, if $c<p_{l} D_{H}(l)-C(m)$ then by virtue of assumption (8c) the slope of $\Delta E C^{C}(\gamma)$ is larger then the slope of $\Delta E C^{s e p}(\gamma)$ at $\gamma=0$. As $\Delta E C^{C}(0)=\Delta E C^{s e p}(0)=0$, this implies that $\Delta E C^{C}(\gamma)>\Delta E C^{\text {sep }}(\gamma)$ for all $\gamma \in(0, \hat{\gamma})$ for some $\hat{\gamma} \in(0,1)$.

To show the third part, we first derive the first derivative of the expected welfare loss under the fully decentralized regime and evaluate it at $\gamma=0$ :

$$
\left.\frac{d \Delta E C^{C}(\gamma)}{d \gamma}\right|_{\gamma=0}=4 C(B)-2 C(A) .
$$

Thus, the slope of $\Delta E C^{D}(\gamma)$ is larger than the slope of $\Delta E C^{s e p}(\gamma)$ at $\gamma=0$ if $2 C(B)>$ $E C_{L H}$. In addition, $\Delta E C^{D}(1)>\Delta E C^{\text {sep }}(1)$ if $2 C(B)>E C_{H H}$. The third part of the proposition follows from the fact that $\Delta E C^{D}(0)=\Delta E C^{\text {sep }}(0)=0$ and both are quadratic functions that can only intersect once in $\gamma \in(0,1)$. 


\section{References}

Aakre, S. and D. T. Rübbelke (2010). Objectives of public economic policy and the adaptation to climate change. Journal of Environmental Planning and Management 53(6), 767-791.

Agrawala, S., F. Bosello, C. Carraro, E. De Cian, E. Lanzi, et al. (2011). Adapting to climate change: costs, benefits, and modelling approaches. International Review of Environmental and Resource Economics 5(3), 245-284.

Akai, N. and M. Sato (2008). Too big or too small? a synthetic view of the commitment problem of interregional transfers. Journal of Urban Economics 64(3), 551-559.

Amundsen, H., F. Berglund, and H. Westskog (2010). Overcoming barriers to climate change adaptationöa question of multilevel governance? Environment and Planning C: Government and Policy 28, 276-289.

Besfamille, M. (2003). Local public works and intergovernmental transfers under asymmetric information. Journal of Public Economics 88(1), 353-375.

Besfamille, M. and B. Lockwood (2008). Bailouts in fedeartions: Is a hard budget constraint always best? International Economic Review 49(2), 577-593.

Bjorvatn, K. and G. Schjelderup (2002). Tax competition and international public goods. International Tax and Public Finance 9(2), $111-120$.

Boadway, R. (1982). On the method of taxation and the provision of local public goods: Comment. American Economic Review 72(4), 846-851.

Boadway, R. and J.-F. Tremblay (2012). Reassessment of the tiebout model. Journal of Public Economics 96(11-12), 1063-1078.

Bordignon, M., P. Manasse, and G. Tabellini (2001). Optimal regional redistribution under asymmetric information. The American Economic Review 91 (3), 709-723.

Breuillé, M.-L. and R. J. Gary-Bobo (2007). Sharing budgetary austerity under free mobility and asymmetric information: An optimal regulation approach to fiscal federalism. Journal of Public Economics 91(5), 1177-1196.

Breuillé, M.-L., T. Madiès, and E. Taugourdeau (2010). Gross versus net equalization scheme in a federation with decentralized leadership. Journal of Urban Economics 68(2), 205-214.

Bruehlhart, M., S. Bucovetsky, and K. Schmidheiny (2015). Taxes in cities. In G. Duranton, J. Henderson, and W. Strange (Eds.), Handbook of Regional and Urban Economics, Vol. 5, pp. 1123-1196. North-Holland.

Bucovetsky, S. (2003). Efficient migration and redistribution. Journal of Public Economics 87(11), 2459-2474.

Bucovetsky, S. (2011). Incentive equivalence with fixed migration costs. Journal of Public Economics 95(11-12), 1292-1301. 
Bucovetsky, S., M. Marchand, and P. Pestieau (1998). Tax competition and revelation of preferences for public expenditure. Journal of Urban Economics 44(3), 367-390.

Buob, S. and G. Stephan (2011). To mitigate or to adapt: How to confront global climate change. European Journal of Political Economy 27(1), 1-16.

Caplan, A. J., R. C. Cornes, and E. C. D. Silva (2000). Pure public goods and income redistribution in a federation with decentralized leadership and imperfect labor mobility. Journal of Public Economics 77(2), 265-284.

Caplan, A. J. and E. C. D. Silva (2011). Impure public goods, matching grant rates and income redistribution in a federation with decentralized leadership and imperfect labor mobility. International Tax and Public Finance 18(3), 322-336.

Cho, I.-K. and D. M. Kreps (1987). Signaling games and stable equilibria. The Quarterly Journal of Economics 102(2), 179-221.

Cornes, R. C. and E. C. Silva (2003). Public good mix in a federation with incomplete information. Journal of Public Economic Theory 5(2), 381-397.

Cremer, H., M. Marchand, and P. Pestieau (1996). Interregional redistribution through tax surcharge. International Tax and Public Finance 3(2), 157-173.

De Bruin, K. C. and R. B. Dellink (2011). How harmful are restrictions on adapting to climate change? Global Environmental Change 21(1), 34-45.

De Bruin, K. C., R. B. Dellink, and R. S. Tol (2009). Ad-dice: an implementation of adaptation in the dice model. Climatic Change 95(1-2), 63-81.

Eichner, T. and M. Runkel (2012). Interjurisdictional spillovers, decentralized policymaking, and the elasticity of capital supply. American Economic Review 102(5), 2349-2357.

Feenstra, J. F., I. Burton, J. B. Smith, and R. S. Tol (1998). Handbook on methods for climate change impact assessment and adaptation strategies. UNEP.

Glicksman, R. L. (2010). Climate change adaptation: A collective action perspective on federalism considerations. Environmental Law 40, 1159-1193.

Goodspeed, T. J. and A. F. Haughwout (2012). On the optimal design of disaster insurance in a federation. Economics of Governance 13(1), 1-27.

Hoel, M. (2004). Interregional interactions and population mobility. Journal of Economic Behavior and Organization 55(3), 419-433.

Hoel, M. and P. Shapiro (2003). Population mobility and transboundary environmental problems. Journal of Public Economics 87(5), 1013-1024.

Hoel, M. and P. Shapiro (2004). Transboundary environmental problems with mobile but heterogeneous populations. Environmental and Resource Economics 27(3), 265-271.

Huber, B. and M. Runkel (2006). Optimal design of intergovernmental grants under asymmetric information. International Tax and Public Finance 13(1), 25-41. 
IPCC (2014). Climate Change 2014: Impacts, Adaptation, and Vulnerability. Part A: Global and Sectoral Aspects. Contribution of Working Group II to the Fifth Assessment Report of the Intergovernmental Panel on Climate Change. Cambridge, UK and New York, USA: Cambridge University Press.

Kane, S. and J. F. Shogren (2000). Linking adaptation and mitigation in climate change policy. Climatic Change 45(1), 75-102.

Köthenbürger, M. (2004). Tax competition in a fiscal union with decentralized leadership. Journal of Urban Economics 55(3), 498-513.

Krysanova, V., C. Dickens, J. Timmerman, C. Varela-Ortega, M. Schlüter, K. Roest, P. Huntjens, F. Jaspers, H. Buiteveld, E. Moreno, et al. (2010). Cross-comparison of climate change adaptation strategies across large river basins in europe, africa and asia. Water Resources Management 24(14), 4121-4160.

Kuhlmey, F. and B. Hintermann (2016). Public provision and local income tax competition. CESifo Working Paper 5789.

Leal Filho, W. (Ed.) (2015). Handbook of climate change adaptation. Heidelberg: Springer.

List, J. A. and C. F. Mason (2001). Optimal institutional arrangements for transboundary pollutants in a second-best world: evidence from a differential game with asymmetric players. Journal of Environmental Economics and Management 42(3), 277-296.

Lockwood, B. (1999). Inter-regional insurance. Journal of Public Economics 72(1), 1-37.

Mansoorian, A. and G. M. Myers (1993). Attachment to home and efficient purchases of population in a fiscal externality economy. Journal of Public Economics 52(1), 117-132.

Myers, G. M. and Y. Y. Papageorgiou (1997). Efficient nash equilibria in a federal economy with migration costs. Regional Science and Urban Economics 27(4), 345-371.

Oates, W. E. (1972). Fiscal Federalism. New York: Harcourt Brace Jovanovich.

Oates, W. E. (2005). Toward a second-generation theory of fiscal federalism. International tax and public finance 12(4), 349-373.

Ogawa, H. and D. E. Wildasin (2009). Think locally, act locally: Spillovers, spillbacks, and efficient decentralized policymaking. American Economic Review 99(4), 1206-1217.

Persson, T. and G. Tabellini (1996). Federal fiscal constitutions: Risk sharing and moral hazard. Econometrica: Journal of the Econometric Society 64(3), 623-646.

Raff, H. and J. D. Wilson (1997). Income redistribution with well-informed local governments. International Tax and Public Finance 4(4), 407-427.

Richter, W. and D. Wellisch (1996). The provision of local public goods and factors in the presence of firm and household mobility. Journal of Public Economics 60(1), 73-93.

Sanguinetti, P. and M. Tommasi (2004). Intergovernmental transfers and fiscal behavior insurance versus aggregate discipline. Journal of International Economics 62(1), 149170. 
Silva, E. C. D. and A. J. Caplan (1997). Transboundary pollution control in federal systems. Journal of Environmental Economics and Management 34(2), 173-186.

Wellisch, D. (1994). Interregional spillovers in the presence of perfect and imperfect household mobility. Journal of Public Economics 55(2), 167-184.

Wilbanks, T. J., P. Leiby, R. Perlack, J. T. Ensminger, and S. B. Wright (2007). Toward an integrated analysis of mitigation and adaptation: some preliminary findings. Mitigation and Adaptation Strategies for Global Change 12(5), 713-725. 